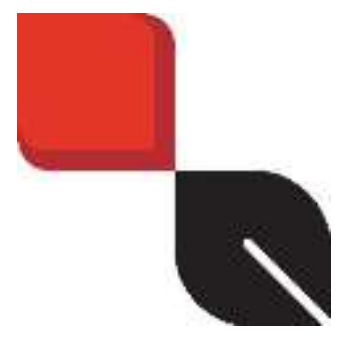

Cuadernos del CILHA n 34 - 2021 | publicación continua

ISSN 1515-6125 | EISSN 1852-9615

https://revistas.uncu.edu.ar/ojs3/index.php/cilha

CC BY-NC 2.5 AR

Recibido: 22/05/2021 Aprobado: 10/06/2021

PP. $1-26$

DOI: https://doi.org/10.48162/rev.34.011

\title{
El género de la desobediencia: resistencias al legado familiar en las hijas de represores en Argentina
}

\author{
Disobedience's Gender: Resistances to the Family Legacy in \\ Daughters of Argentinian Repressors
}

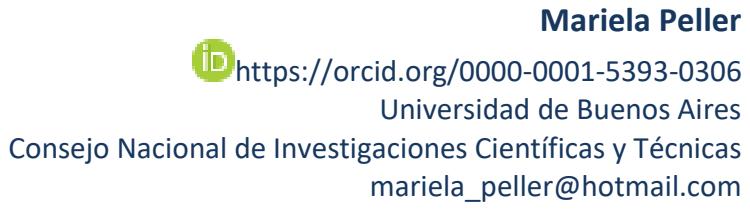

Argentina

\begin{abstract}
Resumen: En 2017 surgieron en la escena pública argentina las voces de hijas de represores, quienes cuestionan el accionar criminal de sus padres durante la última dictadura militar. Algunas de estas hijas -junto con hijos y otros familiares-conformaron el colectivo Historias desobedientes, que interviene en el espacio público a través de diferentes formas de toma de la palabra que implican la defensa de los derechos humanos, la memoria y la justicia. Estas hijas elaboran narrativas atravesadas por perspectivas feministas que les permiten tejer resistencias a los mandatos de silencio y a los legados familiares. Al visibilizar sus experiencias personales, familiares y colectivas aportan datos hasta ahora desconocidos sobre el universo de la vida cotidiana de los agentes de la dictadura. En este artículo, en primer lugar, me refiero al proceso de toma de la palabra y ruptura del pacto de silencio, como un primer paso hacia el alejamiento de los valores familiares. En segundo lugar, rastreo las descripciones sobre la dominación
\end{abstract}


y los atisbos de resistencia al interior del universo familiar. Finalmente, analizo la constitución de vínculos y genealogías de mujeres como una modalidad novedosa de lazo ético-político.

Palabras clave: Argentina, Hijas, Dictadura, Memoria, Resistencia.

Abstract: In 2017, the voices of daughters of repressors emerged on the Argentine public scene, questioning the criminal actions of their parents during the last military dictatorship. Some of these daughters -along with sons and other relatives- formed the collective Historias desobedientes, which intervenes in the public space through different forms of speaking that involve the defense of human rights, memory and justice. These daughters elaborate narratives crossed by feminist perspectives that allow them to weave resistance to the mandates of silence and family legacies. By making their personal, family and collective experiences visible, they provide hitherto unknown data about the universe of everyday life of dictatorship's agents. In this article, first, I refer to the process of taking the floor and breaking the pact of silence, as a first step towards moving away from family values. Second, I track descriptions of domination and glimpses of resistance within the family universe. Finally, I analyze the constitution of ties and genealogies of women as a novel modality of ethical-political bond.

Keywords: Argentina, Daughters, Dictatorship, Memory, Resistance.

"La resistencia de las mujeres también puede realizar recorridos imprevisibles, capaces de encontrar y crear líneas de escape, fugas, vectores que les permiten, en lugar de sobrevivir y encontrar resquicios dentro de las relaciones de poder masculinas, abrir verdaderas fisuras y 'salir' hacia un lugar otro..."

(Pilar Calveiro, Familia y poder, p. 22).

“¿Qué sería de las mujeres sin el amor de las mujeres?” (Marcela Lagarde y de los Ríos, Pacto entre mujeres. Sororidad, p. 124). 


\section{Introducción: nuevas voces de la memoria social}

En la introducción a su libro La lucha por el pasado, Elizabeth Jelin (2017) sostiene que "lo que es silenciado en determinada época puede emerger con voz fuerte después; lo que es importante para cierto período puede perder relevancia en el futuro, mientras otros temas o cuestiones ocupan todo el interés" (p. 11). Las luchas alrededor de la construcción de la memoria social posibilitan cambios en los relatos y la emergencia de nuevas voces antes impensables. En este sentido, hasta la fecha, los debates sobre la denominada segunda generación dentro de los estudios de memoria latinoamericanos venían enfocándose casi exclusivamente en las experiencias de hijos e hijas de víctimas de la violencia estatal, pero desde mediados de 2017, en un contexto global en que la derecha ha ganado fuerza, comenzaron a surgir nuevas voces que muestran otras visiones intergeneracionales sobre las dictaduras de la región. En particular, surgieron con bastante fuerza las voces de las hijas e hijos de perpetradores y colaboradores de violaciones a los derechos humanos y crímenes de lesa humanidad, que reniegan de los actos cometidos por sus progenitores e intentan romper con los pactos de silencio y los legados familiares criminales. Estas voces se posicionan en defensa de los derechos humanos y consideran que sus padres deben ser juzgados y condenados por los crímenes que cometieron durante las dictaduras militares de la región. No solo les solicitan a sus padres que hablen y den información sobre las personas desaparecidas y los niños apropiados, sino que también han pedido la modificación de la ley para poder declarar en juicios en su contra (Llonto, 2020).

Una serie de trabajos recientes refieren al denominado "giro hacia el perpetrador" en producciones culturales y narrativas sociales, a diferencia de periodos previos en los que habían predominado las voces testimoniales de las víctimas y sus familiares en sociedades pos-conflicto y pos-dictatoriales (Feld y Salvi, 2019; Crownshaw, 2011; Zylberman, 2020). En esta línea se hace referencia a la aparición de producciones culturales elaboradas por la "generación pos-perpetradores", aquella que trabaja sobre responsabilidades no propias sino heredadas. Este giro reciente hacia los perpetradores se relaciona con que las nuevas generaciones comienzan a tomar en sus propias manos la memoria del pasado (Moral, Bayer y Canet, 2020). Por múltiples factores, las voces de las descendencias de perpetradores son voces incómodas, que tensionan las categorías de "víctimas", "victimarios" y "cómplices", la idea de "sujeto implicado" 
resulta fecunda para referirse a estas subjetividades que presentan implicaciones complejas y posicionamientos dinámicos respecto de los acontecimientos criminales del pasado (Rothberg, 2019; Lazzara, 2020).

En Argentina, estas voces novedosas se hicieron públicas cuando Mariana Dopazo, ex hija del represor Miguel Etchecolatz, narró su participación en la marcha contra el fallo que permitía la condonación de los años de prisión a los agentes implicados en la última dictadura, sanción conocida como " $2 \times 1$ " (Mannarino, 2017) 1 . A partir de ese momento, hijas e hijos de represores comenzaron a contactarse por redes sociales y, tras una serie de encuentros y desencuentros, conformaron dos grupos de pertenencia. Por un lado, algunas hijas, hijos y familiares fundaron el colectivo Historias desobedientes, cuya presidenta es Analía Kalinec ${ }^{2}$. Por otro lado, existe un grupo más disperso, que en un momento se denominó Ex hijos y ex hijas de genocidas, nucleados alrededor de Mariana Dopazo y Erika Lederer, pero que en la actualidad no parece funcionar de modo orgánico ${ }^{3}$.

La aparición pública de estas voces constituye un acontecimiento político importante porque revelan experiencias en primera persona hasta ahora desconocidas sobre la vida cotidiana y los núcleos cercanos de los represores. Por otra parte, a partir de sus testimonios y posturas políticas progresistas se alían con diferentes grupos movilizados contra el neoliberalismo, el patriarcado y a favor de los derechos humanos. En un primer momento, hubo cierta desconfianza sobre las intenciones de estas hijas e hijos.

\footnotetext{
${ }^{1}$ Mariana Dopazo es psicoanalista. Es la ex hija del represor Miguel Etchecolatz, en 2014 presentó un pedido a la justicia de sustracción de su apellido paterno y sustitución por el materno. Etchecolatz fue Director de Investigaciones de la Policía de la Provincia de Buenos Aires entre marzo de 1976 y fines de 1977. Coordinó los Grupos de Tareas y los 21 centros clandestinos de detención pertenecientes al denominado Circuito Camps. Mariana se basó en el caso de Rita Vagliati para llevar adelante su causa.

${ }^{2}$ Analía Kalinec es psicóloga, docente y delegada sindical. Es hija de Eduardo Emilio Kalinec, ex oficial de la Policía Federal, quien ha sido juzgado por su participación en el circuito ABO (Atlético-Banco-Olimpo) y condenado a la pena de prisión perpetua. Recientemente se formaron colectivos de Historias desobedientes en Chile (2019) y en Brasil (2021).

${ }^{3}$ Estas divisiones entre grupos no son tajantes. Por ejemplo, si bien Mariana Dopazo no integra Historias desobedientes, suele participar de las actividades organizadas por el colectivo. La cuestión del modo de denominación respecto de los padres parece ser uno de los puntos de desencuentro entre los grupos (Lipis, 2019, pp. 194-195).
}

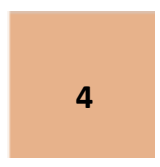

Cuadernos del CILHA n $34-2021$ 
Los organismos de derechos humanos temieron que se tratara de un discurso con tonos negacionistas y reconciliatorios, como los pertenecientes a descendientes de perpetradores que no cuestionan o que defienden el accionar criminal de sus padres ${ }^{4}$. Esta lectura ambivalente tiene sentido se consideramos que, en los últimos años en la Argentina - pero también a escala regional y global-, asistimos a una reacción de fuerzas conservadoras tradicionales y recicladas (Pedrido, 2021). Pero con el tiempo, esta nueva voz se encargó de hacer pública su posición de búsqueda de Memoria, verdad y justicia, lo que les permitió ser reconocidos y legitimados por integrantes del movimiento de derechos humanos 5 .

Diversos procesos sociales colaboraron en el desplazamiento subjetivo desde una experiencia personal trágica hacia la salida al espacio público y la conformación de un colectivo político. Estas nuevas voces encontraron sus condiciones más inmediatas de emergencia y escucha social con el repudio masivo a las políticas de la memoria regresivas del gobierno de Mauricio Macri (2015-2019) pero sus posibilidades de emergencia de más largo aliento se fueron tejiendo con la larga lucha del movimiento de derechos humanos y el movimiento feminista y de mujeres. Estas voces emergentes exhiben que los debates públicos sobre las responsabilidades criminales, los procesos de construcción de la verdad y los avances en la justicia tuvieron efectos en las propias familias de los perpetradores, ya que colaboraron a que las segundas generaciones fueran interpeladas a responder socialmente por las acciones criminales de sus padres y se posicionaran contra las lealtades familiares. En efecto, en los relatos de las hijas y los hijos, los juicios a los represores, que implican un reconocimiento por parte del Estado de los crímenes cometidos por sus padres, aparecen como una inscripción del hecho en la realidad, que les permitió comenzar a alejarse de su núcleo familiar y realizar un proceso de desafiliación. Asimismo, estas voces no podrían haber sido

\footnotetext{
${ }^{4}$ Mario Santucho (2017) realiza un mapeo de los colectivos de familiares que defienden a los represores y sitúa la emergencia de Historias Desobedientes en un contexto de prevalencia de discursos revisionistas y reconciliadores.

${ }^{5}$ En el último tiempo, Historias desobedientes adquirió reconocimiento público y legitimidad social, mediante sus participaciones en Jornadas en el Centro Cultural de la Memoria Haroldo Conti y la realización del "Primer encuentro internacional de Historias desobedientes", en 2018 en la Facultad de Ciencias Sociales de Universidad de Buenos Aires, auspiciado por variedad de organizaciones y personalidades vinculadas a los derechos humanos.
}

Cuadernos del CILHA n $34-2021$ 
enunciadas ni escuchadas sin la presencia en la esfera pública del movimiento feminista, con sus cuestionamientos a la naturalización patriarcal de los lazos de sangre y la institución familiar como un espacio de felicidad (Ahmed, 2019). En Argentina, son las hijas mujeres quienes lideran el cuestionamiento de los legados familiares y del mandato de silencio. No es casual que la primera vez que el colectivo Historias desobedientes salió a la calle con su bandera haya sido un 3 de junio (2017), durante la marcha del Ni una menos contra los femicidios, suceso que evidencia el compromiso del colectivo con la crítica al patriarcado y a la violencia machista.

Dada la novedad de este actor social, los trabajos previos sobre el tema son escasos y recientes. La mayoría se dedica al estudio del surgimiento de estas nuevas voces de la memoria (Raso, 2017; Rousseaux, 2017; Scocco, 2017). Entre las intervenciones más significativas se encuentran las de Leonor Arfuch (2017), Teresa Basile (2020) y Ana Guglielmucci (2020) que establecen genealogías al insertar estas voces al interior de temporalidades de la memoria más amplias y muestran algunos de los aportes de las segundas generaciones para conocer el universo de los perpetradores. Otros trabajos examinan films que presentan la perspectiva de los descendientes de perpetradores en Argentina e indagan en las rupturas con las lealtades familiares y los pactos de silencio (Zylberman, 2020; Moral, Bayer y Canet, 2020).

Considerando esa base de trabajos, en este artículo propongo realizar un aporte específico en tanto presento una lectura desde el género, que entiende los relatos y las prácticas actuales de las hijas desobedientes como gestos de resistencia con ribetes feministas ${ }^{6}$. A partir de su aparición pública, estas hijas han puesto a circular relatos testimoniales y autoficcionales que, desde perspectivas que cuestionan la violencia machista y el patriarcado, visibilizan sus experiencias personales y colectivas como descendientes de represores. Son narraciones que rompen con el mandato de silencio al difundir vivencias de orden privado y familiar, que permiten recuperar parte del universo de vida de los perpetradores: sus ideas, sus creencias, sus valores, su modo de

\footnotetext{
${ }^{6}$ Hasta la fecha, pocos trabajos realizan una lectura específicamente en clave de género. En un artículo previo, analicé las historias de las hijas desobedientes en serie con narrativas de hijas de desaparecidos, a partir de la noción de "aguafiestas" (Peller, 2020). Asimismo, María Luz Gómez Groppa (2020) examina la desobediencia feminista en narrativas posdictatoriales escritas por mujeres, referidas al pasado reciente e incluye relatos de las hijas de represores.
} 
organización familiar, sus vínculos afectivos, entre otras cuestiones. Los relatos de las segundas generaciones difieren de la palabra pública que han producido los represores y otorgan un nuevo saber sobre el pasado reciente, que es capital para la ampliación de los procesos de memoria.

Como señalan Claudia Feld y Valentina Salvi (2019), diversos obstáculos hicieron que las historias de vida de los perpetradores se mantuvieran prácticamente inexploradas por décadas. Uno de ellos se refiere al dilema moral y político que implica autorizar la palabra y la escucha de los represores. Frente al insuficiente conocimiento de las vidas cotidianas de los agentes que llevaron adelante el terror estatal, las voces de sus descendientes tienen la particularidad de acercarnos cierto saber y de hacerlo desde un posicionamiento ético-político que nos permite como sociedad escucharlos y sostenerlos en su experiencia de dar testimonio.

En particular, en este artículo examino los relatos presentes en Escritos desobedientes (Bartalini et al., 2018) y Nosotrxs, historias desobedientes (Kalinec, 2020), y la autoficción La mujer sin fondo de Stella Duacastella (2020) pero también presto atención a notas periodísticas, entrevistas y films (Lipis, 2019; Dores, 2019; Canal Encuentro, 2020). Estas narrativas permiten acercarse a las articulaciones entre la violencia ejercida por los perpetradores como actores de prácticas sociales criminales y la violencia de género (a veces más sutil, a veces más evidente) en las dinámicas familiares. En este punto, sigo los trabajos de autoras que intentan comprender las posibles interconexiones entre violencia familiar o doméstica y otras violencias ejercidas en el ámbito público (Calveiro, 2005; Snyder, 2019; Fries, 2010).

En particular, me interesa comprender lo que llamo el género de la desobediencia, es decir, los modos en que las hijas, a través de diversas estrategias feministas, han podido tejer resistencias a los mandatos de silencio y a los legados de violencia7. En primer lugar, me refiero al proceso de toma de la palabra y ruptura del silencio, como primer paso en el camino hacia el alejamiento de los valores familiares. En segundo lugar, rastreo las descripciones sobre la dominación y los atisbos de resistencia al interior del

\footnotetext{
${ }^{7}$ A pesar de que hay varones en el colectivo, estudio el caso de las hijas mujeres porque son quienes lideran la agrupación y presentan mayor visibilidad pública y porque también se trata de un grupo de voces que se caracteriza por su impronta feminista.
}

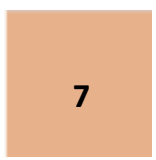

Cuadernos del CILHA n $34-2021$ 
universo familiar endogámico en el que crecieron. En tercer lugar, analizo la constitución de vínculos y genealogías de mujeres como formas novedosas de lazo ético-político. Finalmente, cierro con unas breves palabras a modo de conclusión.

\section{Resistir el mandato de silencio}

En Argentina, en 2017, asistimos a una especie de boom mediático de testimonios, notas y entrevistas a las hijas de represores, quienes relataban las experiencias que las habían llevado a cuestionar en la actualidad el accionar criminal de sus padres durante la última dictadura militar. El caso de Mariana Dopazo desencadenó la seguidilla de intervenciones, tras dar su testimonio en la nota titulada "Marché contra mi padre genocida" (Mannarino, 2017) ${ }^{8}$. A partir de ese momento, las hijas de represores fueron entrevistadas por una multiplicidad de canales de televisión y diarios locales e internacionales y cobraron inmensa visibilidad y difusión en el espacio público.

Estas posibilidades de difusión y escucha pública se fueron tejiendo a lo largo de los años, subrepticia y lentamente, mediante la interrelación de los procesos sociales con los personales y psíquicos de las hijas. El avance en las políticas de derechos humanos y la contundencia de los juicios por crímenes de lesa humanidad funcionaron como una inscripción de la ley en las vidas de estas hijas que, en muchos casos, les confirmó sospechas que ya tenían, les sacó la venda de los ojos o les permitió empezar a nombrar un "saber-no sabido" (Violi, 2020a). Otro tanto hicieron las organizaciones de mujeres y el movimiento feminista que puso a circular -cada vez con mayor impacto culturaldiscursos sociales que habilitan a las mujeres a cuestionar situaciones de violencia y poder familiares y sociales, que antes no reconocían como tales.

\footnotetext{
${ }^{8}$ En Argentina, "represor" es la categoría nativa más extendida para referirse a los miembros de las fuerzas armadas y de seguridad que participaron en el terrorismo de Estado. Por su parte, la categoría "genocida" adquirió presencia social tras la sentencia a cadena perpetua a Miguel Etchecolatz en 2006 que fue condenado por las acciones que realizó "en el marco de un genocidio". La cuestión acerca de la denominación como "genocidio" de la última dictadura argentina es todavía un debate académico no saldado (Feld y Salvi, 2019, p. 16). No obstante, como señala Basile (2020) las hijas desobedientes utilizan dicha noción dado que parecen seguir la lectura que realiza Daniel Feierstein (2007) sobre el periodo. Para una historización de la palabra represor en Argentina se pude consultar el trabajo de Analía Goldentul (2016).
}

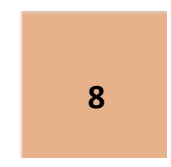

Cuadernos del CILHA n $34-2021$ 
Por otra parte, las hijas como sujetos individuales también fueron haciendo un trabajo de reflexión sobre sí mismas que les permitió en la actualidad alejarse de los mandatos familiares y militares, para ubicarse en la senda de los derechos humanos y la crítica de la violencia machista y dictatorial. Es importante señalar que este posicionamiento en contra del mandato de silencio y las lealtades familiares-militares, es novedoso en cuanto a su visibilidad, presencia en la espacio público y conformación de un colectivo político, pero en años previos ya habían aparecido hijas que repudiaron públicamente a sus padres represores, como los de Rita Vagliati y Vanina Falco, quienes han sido faros en el camino de las otras hijas 9 .

Las hijas desobedientes han tomado la palabra en una multiplicidad de formas (habla, escritura, testimonio, declaración) y en una variedad de espacios (hogares, lugares de trabajo y de estudio, escuelas de los hijos, juicios, medios de comunicación, charlas, libros). Tanto la ruptura del silencio como el ejercicio de la desobediencia que dicha ruptura supone son acciones que conllevan fuertes cargas simbólicas. No se trata de ir contra los secretos y de desobedecer órdenes al interior de cualquier familia. En el marco de estas familias militares y policiales las nociones de obediencia y de pacto de silencio poseen sentidos sociales específicos. A partir de la transición democrática, la idea de "pacto de silencio", una categoría nativa surgida en el campo de los derechos humanos, refiere a la negativa de las miembros de las fuerzas armadas y de seguridad implicados en la represión clandestina, a aportar informaciones que permitieran conocer y juzgar los crímenes cometidos durante la dictadura, como el destino de los desaparecidos, los casos de apropiación de niños y niñas, las cadenas de responsabilidad, entre otras cuestiones. Salvo algunas excepciones, la mayoría de los datos han provenido de las víctimas y de las investigaciones de los organismos de derechos humanos (Feld y Salvi, 2019, p. 11). Asimismo, la noción de desobediencia que

\footnotetext{
${ }^{9}$ Rita Vagliati es la ex hija del ex comisario Valentín Milton Pretti (fallecido), quien participó en la policía bonaerense durante la dictadura bajo las órdenes de Camps. Fue torturador en el Pozo de Banfield, en el Pozo de Quilmes y en Puerto Vasco. En 2005, Rita realizó un pedido a la justicia para cambiarse el apellido por el de su madre y su caso se hizo público en algunos medios de comunicación. Mariana Dopazo se basó en su caso para llevar adelante su propia causa judicial. Por su parte, Vanina Falco es la hija de Luis Antonio Falco, ex agente de inteligencia de la Policía Federal y apropiador de Juan Cabandié. Vanina declaró contra su padre en el juicio por apropiación en 2011, pudo hacerlo porque su testimonio ya había cobrado publicidad cuando actuó en la obra de teatro Mi vida después de Lola Arias.
}

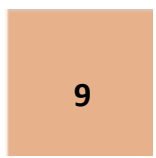

Cuadernos del CILHA n $34-2021$ 
fue adoptada por las hijas para referirse a sí mismas y a las acciones que las alejan de los valores de sus progenitores represores, posee también una connotación social al contrastar con la idea de "obediencia debida", perteneciente al discurso militar, que sostiene que muchas de las acciones realizadas en el marco de la represión clandestina fueran legítimas en tanto se trató de cumplir órdenes que emanaban de un superior en la cadena de mandos (Ibidem, p. 17).

Pilar Calveiro (2005) estudia el funcionamiento del poder y la resistencia al interior de las familias y encuentra la existencia de dos líneas principales, que establecen relaciones asimétricas entre los miembros ${ }^{10}$. Una de esas líneas implica relaciones de género y se dirige de hombres a mujeres y la otra, es intergeneracional, de padres y madres a hijas e hijos. En dicho escenario de redes de poder, las hijas mujeres suelen ser quienes están doblemente subordinadas. En el caso de las hijas desobedientes romper silencios y secretos implicó un plus de resistencia, dada la carga de significación y los poderes militares implicados en esos mandatos. Desobedecer supuso no solo ir contra el padre $-y$ en ocasiones también la madre-, sino también cuestionar el discurso masculino machista de las castas militares y policiales vinculadas al terror estatal. Como intentaré mostrar a continuación con algunos ejemplos, el acto de tomar la palabra es un modo de resistencia al poder y es también producción de subjetividades nuevas, en tanto habilita la posibilidad de tramitación de una historia personal trágica ${ }^{11}$.

En una entrevista personal que le realicé en febrero de 2019, Analía Kalinec narraba que fue en 2008 cuando elevaron la causa de su padre a juicio oral que se produjo un punto de inflexión en su vida. Hasta ese momento todavía se mantenía cercana a las

\footnotetext{
${ }^{10}$ Calveiro (2005) intenta comprender las formas en que el funcionamiento del poder en la familia y en la sociedad se implican. Escribe: "familia y sociedad son ámbitos profundamente interconectados, que 'resuenan' en frecuencias afines y en los que se juegan relaciones de poder que traspasan las fronteras, interpenetrando los espacios tanto públicos como privados. En consecuencia, las estrategias, mecánicas y procedimientos del poder y la resistencia que se emplean dentro de la familia pueden sugerir, echar luz e incluso explicar algunos de estos mismos intercambios en ámbitos más amplios de la sociedad" (p. 9).

${ }^{11}$ Las hijas desobedientes se encargan de elidir la figura de víctima para sí mismas puesto que insisten en que dicho estatuto corresponde solo a quienes han vivido en carne propia la represión y la desaparición por parte de agentes de la dictadura. No obstante, como señala Basile, "todos los hijos/as de militares y policías que actuaron en la maquinaria represiva son niños víctimas de los setenta, en tanto han heredado una historia maldita en la cual no participaron y de la que no son responsables" (2020, p. 132).
}

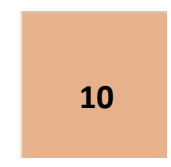

Cuadernos del CILHA n $34-2021$ 
creencias familiares y creía que su padre estaba siendo juzgado por error. Pero en 2008 mantiene una conversación con él en la que lo descubre sosteniendo un discurso que hasta ese momento no había escuchado. Escucha a su padre justificar la tortura de los "subversivos". Ese día, Analía hace un clic a partir del cual empieza a hablar no solo hacia el interior de su familia, sino también hacia afuera. Comienza a contar compulsiva y públicamente su historia.

Entonces ahí empieza un intento familiar de alejarme, como que yo era algo peligroso para la familia, así lo leo yo. Y ahí arranca mi compulsión a hablar, como lo interpreto ahora, ahí es cuando Gino [uno de sus hijos] en salita de cuatro les cuenta a sus compañeritos de jardín que su abuelo estaba preso y yo me tengo que presentar en el jardín porque me llamaron. [...] En la Facultad también lo empiezo a circular. Frente a esta necesidad de distanciarme, a temer también que reconozcan mi apellido, me pasó en la escuela que se me acerque una compañera y me pregunte porque tiene a su hermano desaparecido en el Olimpo. En ese marco, yo me quedo como buscando las respuestas al interior de la familia, como diciendo hablemos de esto, expliquémoslo, qué está pasando acá. Y donde me encuentro que no hay respuesta. Que la respuesta es que yo me tengo que ir, que yo no pertenezco ahí, que yo soy una traidora, por decirlo de alguna manera... (Kalinec, A. Comunicación personal, 20 de febrero de 2019)

En 2010, Stella Duacastella, actual integrante de Historias desobedientes, publicaba por primera vez su libro La mujer sin fondo (2020), novela autoficcional que narra su historia de vida como hija de un militar participante de crímenes durante la última dictadura. ${ }^{12}$ La protagonista de la novela es Inés, psicóloga, madre de dos hijos, felizmente casada e hija del coronel Ramón Fortuna. Frente a una depresión profunda que la deja sin fuerzas para seguir con su vida, su psiquiatra le recomienda escribir su historia para intentar comprender y poder quizás comenzar a sanar las heridas. La escritura se muestra como

\footnotetext{
12 Stella Duacastella nació en Formosa en 1956. Es psicóloga y hace años que utiliza el apellido de su marido. Es la hija del teniente coronel Omar Ramón Capecce, médico del Hospital Militar de Campo de Mayo, que estuvo involucrado en el funcionamiento de la maternidad clandestina y en el destino de los niños nacidos allí. Capecce estuvo preso y falleció sin ser condenado, luego de que las causas en su contra fueran suspendidas por su estado de salud.
} 
un viaje al pasado familiar que le permite recordar para entender los motivos de su actual tristeza y procurar modificarla.

Levanté la lapicera. Ahora que apenas podía conmigo misma, miraba para atrás y casi podía asegurar que había sido feliz sin darme cuenta. Pero eso era antes. ¿Cuándo había cambiado? ¿Cuándo me había empezado a convertir en esa mujer que me disgustaba tanto?

Sería mejor empezar por el principio. Remontarse tan lejos como lleguen los recuerdos y presentármelos a mí misma para intentar reconocerme en ellos. La idea no me entusiasma porque nada me entusiasma. Pero era un comienzo. El comienzo del viaje. (p. 27)

Por su parte, las integrantes de la agrupación Historias desobedientes vienen desarrollando desde su creación como colectivo una "política de la letra" (Basile, 2020, p. 136) a través de diferentes estrategias orales y escritas. Manifiestan, asimismo, una especie de compulsión por la palabra como si algo se hubiera liberado y necesitara ver la luz. Escribieron comunicados en redes sociales y ensayos que publicaron en libros, dieron sus testimonios en entrevistas en medios de comunicación escritos y audiovisuales, hablaron en films, produjeron y actuaron una performance estética (Colectivo Historias Desobedientes, 2020). En el Manifiesto que abre su primer libro se puede leer:

A medida que nos fuimos conociendo [...] descubrimos que la mayoría de nosotres anhelaba practicar o practicaba ya la expresión a través de la palabra (escrita u oral) como forma de búsqueda personal y herramienta para tejer comunidades de acción, en desafío al silencio que pretendieron imponernos desde pequeñes. (Bartalini et al., 2018, pp. 9-10) ${ }^{13}$

Los ejemplos citados permiten observar formas de toma de la palabra, que implican formas de resistencia al mandato familiar de silencio. Hablar, escribir, publicar -de un modo prácticamente compulsivo- son estrategias que las hijas de represores se han dado como un primer paso en el camino hacia el alejamiento de los valores familiares.

\footnotetext{
${ }^{13}$ Otra política de la letra es la ortografía inclusiva, que eligen llevar adelante al utilizar la letra "e" y/o la " $\mathrm{x}$ " como formas neutras y englobantes, en reemplazo de la distinción genérica tradicional.
} 
Se trata de una acción con fuerte carga simbólica y social, en tanto permite vislumbrar el universo familiar de los agentes del terrorismo de Estado, un territorio hasta ahora poco conocido. Diversos trabajos que analizan testimonios femeninos han señalado que cuando las mujeres hablan producen desplazamientos en los discursos masculinos hegemónicos en tanto refieren a situaciones que iluminan los modos en que el poder, las desigualdades y las ideologías de género actúan en la vida de los sujetos y en las sociedades (Oberti, 2015; Sutton, 2018). En el caso de los relatos de las hijas de represores, como veremos a continuación, la toma de la palabra implica la difusión de los detalles de una vida familiar endogámica, en la que primaba la ley del padre, pero en la que también existieron modalidades de resistencia.

\section{Resistir la ley del padre y la endogamia familiar}

Las familias militares y policiales en las que crecieron las hijas desobedientes se organizan sobre el modelo de familia tradicional. Una familia nuclear y caracterizada por la convivencia de un matrimonio monogámico y sus hijos, en la que sexualidad, procreación y convivencia coinciden en el espacio "privado" del ámbito doméstico. Este modelo de familia se concibe como "natural", anclada en la biología y conlleva una concepción cristiana de la moralidad y la normalidad. Tiende a ser una familia patriarcal, donde el "jefe de familia" concentra el poder y tanto los hijos y las hijas como la esposamadre desempeñan papeles anclados en la subordinación al jefe. En este modelo el parentesco es el criterio básico para la asunción de responsabilidades y obligaciones hacia los otros miembros, mientras que la consanguinidad une simbólicamente a las generaciones y configura las identidades (Jelin, 1998). Dadas estas características, la familia como institución social es un espacio paradójico, simultáneamente lugar de afecto e intimidad y ámbito privilegiado de la violencia (Jelin, 1998; Calveiro, 2005).

En las familias de represores -tal como las conocemos a través de los relatos de las hijas- los rasgos tradicionales se exacerban y se hacen más rígidos e inflexibles, al asumir como propias las reglas de comportamiento, las creencias y los valores castrenses. Si la violencia tiene como única función el mantenimiento o la profundización de una relación de dominio (Calveiro, 2005, p. 45), al interior de estas familias los vectores de poder se profundizan y toda resistencia es visualizada como 
más riesgosa porque asume connotaciones derivadas de las nociones de obediencia y las creencias en las jerarquías que articulan el discurso de las fuerzas de seguridad.

Si bien las hijas nos ofrecen descripciones variadas acerca del universo familiar, tienen en común el predominio de la línea de poder del padre hacia hijas e hijos, pero también hacia la esposa. Las madres suelen aparecer en los relatos como acatadoras, sumisas y obedientes, pero también en ocasiones pueden emerger mintiendo y rebelándose a la norma paterna. Son familias organizadas como un circuito cerrado, aislado de terceros, quienes suelen ser entendidos como amenazas. Lo que ocurrió al interior de la familia o fue realizado por alguno de sus miembros debe permanecer en secreto, de allí la fuerza que tiene el mandato de silencio. Dentro de ese universo, las hijas y las madres/esposas parecen estar viviendo en "cautiverio", para usar la idea de Marcela Lagarde. "Las mujeres están cautivas porque han sido privadas de autonomía, de independencia para vivir, del gobierno sobre sí mismas, de la posibilidad de escoger, y de la capacidad de decidir" (2005, pp. 151-152). En una entrevista, Mariana Dopazo habla de sus recuerdos de infancia, de la vida social endogámica que llevaban y de cómo cambiaba el ambiente familiar a la noche cuando su padre regresaba del trabajo. Se rememora a sí misma como una niña sola entre adultos en espacios pertenecientes a las fuerzas policiales, jugando entre armas, uniformes y custodias. Así habla de su infancia:

La potencia cruel de Etchecolatz tenía la efectividad de amedrentar al otro. Entonces, esas vivencias eran de mandatos de silencio, de esto no se habla, la palabra que circulaba era muy corta, no se podía hablar mucho [...] Cuando volvía de la jefatura, [...] reinaba el más absoluto silencio y ahí cambiaba radicalmente la dinámica de la casa, él se iba a su cuarto y comía solo en la cama, digamos que no había una mesa familiar donde comer, lo cual está bien, porque de familiar eso no tenía nada. En todo caso, lo familiar era lo siniestro no lo amoroso. (Canal Encuentro, 2020)

La falta de afecto y de vinculación amorosa con su padre fue uno de los fundamentos que Mariana esgrimió en la causa judicial en la que solicitó cambiarse el apellido por el de su madre (Dopazo, 2020). Y fue luego de que la justicia habilitó dicho cambio que Mariana se animó a salir por primera vez a una marcha en el espacio público, mezclarse 
entre los cuerpos y vivir la experiencia de lo colectivo. Se emociona cuando recuerda ese momento de habitar la calle con otros: "Es algo conmovedor, es algo que me empezó a pasar y que no lo pude dejar más, me parece que porque también lo anhelé mucho" (Canal Encuentro, 2020). Sus corrimientos subjetivos y políticos son múltiples: poder hablar, manifestarse en la calle, abandonar los mandatos familiares, repudiar al propio padre, permitirse cuestionar también a la madre. Son desobediencias que se dirigen específicamente contra su progenitor pero que también rompen con todo el sistema de creencias patriarcales de la Patria Militar (Filc, 1997).

En La mujer sin fondo de Stella Duacastella también asistimos a la descripción de la dominación del padre al interior de la familia.

Mi padre, un militar que había ascendido de rango con rapidez, como estímulo por aceptar destinos poco convenientes, era un hombre elegante, muy buen mozo, de modales distinguidos, y más bien parco en sus expresiones: en general nada demostrativo con su mujer y sus hijas. Creía que la disciplina familiar era su única función en la casa, y la aplicaba con cinturón y castigos cada vez que tenía oportunidad. (Duacastella, 2020, p. 30)

La madre se mostraba sumisa y obediente en presencia del padre, pero le mentía en múltiples situaciones. Escuchar la novela de la tarde, que estaba prohibida, era una de las mentiras más recurrentes que narra Inés, la protagonista de la novela. Las dos hijas, la madre y la criada se complotaban contra el padre cuando no estaba y resistían sus mandatos, reían y hacían chistes durante la hora y media que duraban las apasionadas historias amorosas. En las narraciones de estas hijas, las madres aparecen como una figura ambigua en el circuito familiar en tanto ocupan al mismo tiempo una posición resistente (en relación con el marido) y de poder (en relación con su descendencia). Diferentes sujetos pueden ocupar lugares de dominio o de subordinación, según su posición contextual.

La historia de Analía Kalinec sobre la relación afectiva con su padre es diferente y nos deja entrever que, en ocasiones, el amor puede funcionar como instrumento del poder al interior de la familia: 
El amor parece ser una realidad de signo inverso a la del poder. Sin embargo, es indudable que el recurso del amor suele ser la trampa, el lazo con el que se sujeta al que está en posición de desventaja. Con frecuencia es también el velo tras el que se disimulan las relaciones de dominio, de manera que puede tener un papel fundamental en su preservación. (Calveiro, 2005, p. 61)

En sus primeros testimonios Analía - a diferencia de otras hijas - hacía referencias al afecto y al amor que había mantenido con su padre en la infancia (Arenes y Pikielny, 2016). Pero a medida que se fue distanciando de su familia - por iniciativa propia pero también porque su padre, su madre y sus hermanas la alejan por traidora - comienza a deconstruir esa narrativa de la familia feliz y recuerda el pasado familiar de otra manera. Empieza a cuestionar no solo al padre, sino también a interpelar a la madre acerca de su ambigua posición en el espacio familiar, en tanto sostenedora de la ley paterna. Esto señalaba en una entrevista:

En mi familia no había discusiones, pero porque mi mamá estaba totalmente sometida a todo lo que era la voluntad de mi viejo y nosotras cuatro igual. Fijate que cuando yo un poco me corrí, mi viejo hoy me está haciendo un juicio para declararme indigna y desheredarme. Entonces, es esto, era todo armonioso hasta que alguien llegaba a contradecir algo. Entonces, bueno desde ese lugar también lo leo. Sí, lo ubico a mi viejo como en un intento de ser afectuoso, de hacer demostraciones de cariño expresas, de también una violencia contenida que él tenía pero que no la ejercía sobre nosotras y sobre mi mamá, por lo menos no físicamente. No recuerdo tampoco insultos. Recuerdo también como un cuidado, como de preservar o de hacerlo por otras vías, no sé. Esto, por ejemplo, que te mandabas algún moco o se te volcaba algo y decía 'umm cuando yo era medio salame a mí me pasaba lo mismo', ¿me entendés? Pero bueno, nada, esto, mi mamá [en una carta que me escribió] habla de que mi padre es un Dios padre todo poderoso. El hombre de su vida. A quien ella ama y va a defender siempre. Mi mamá lo conoció con 15 años. No tuvo otro novio nunca. Y a los 18 se casó y a los 24 ya tenía cuatro hijas. Entonces, también leerla ahí, siempre, sin justificarla, ¿̇no?. (Kalinec, A. Comunicación personal, 20 de febrero de 2019) 
Cuando la madre muere en 2015, Analía puede empezar a rever el lugar materno ocupado en familia. Ese fallecimiento marca la conformación de dos bandos insoslayables. Como consecuencia del distanciamiento y los repudios públicos contra su padre, en febrero de 2019, recibió una demanda por "indignidad" (figura contemplada en el Código Civil y Comercial) de parte de su padre y sus dos hermanas menores, quienes forman parte de la Policía Federal. La demanda tiene como finalidad excluirla de la herencia de su madre. El expediente sostiene que Analía ha sido detectada por grupos activistas en la Universidad, que la condujeron a distanciarse de la familia y a hacer declaraciones públicas "agraviantes, difamatorias y falaces". El expediente parece leer el presente desde las claves del pasado, recupera el discurso militar sobre los modos en que la subversión operó en los años setenta para infiltrarse y penetrar al interior de las buenas familias (Peller, 2020). Frente a la salida pública de Analía y el comienzo de su vínculo con otros que escapan al espacio endogámico de la familia policial, el padre y las hermanas reaccionan e intentan desheredarla. La violencia permanece oculta y naturalizada como no violencia hasta que es necesario mostrarla para no perder el dominio sobre el otro (Calveiro, 2005, p. 39).

Los relatos de las hijas dan cuenta de desplazamientos subjetivos y políticos desde una posición de sumisión al silencio y a las lealtades familiares hacia la asunción de una responsabilidad pública y colectiva en favor de los derechos humanos. ${ }^{14}$ Para explicar la contundencia de sus actos de desobediencia se suele hacer referencia a que el peor destino de un hombre es el desprecio de sus propios hijos o a que el repudio cobra mayor fuerza porque proviene del interior de la propia familia, de su descendencia. Mucho se ha dicho sobre el "familismo" (Jelin, 2017) presente en los organismos de derechos humanos, que refiere a la primacía de los lazos de parentesco y la biología para la justificación de los reclamos por Memoria, Verdad y Justicia, en detrimento de otros motivos ideológicos, políticos o éticos. ${ }^{15}$ Las hijas desobedientes realizan una

\footnotetext{
${ }^{14}$ En unas jornadas realizadas en abril de 2021, en las que compartí parte de la investigación que presento en este artículo, Pierre Ostiguy advertía acerca del cuidado que debemos tener como sociedad, pero también como investigadores, de caer en la tentación de realizar lecturas de los procesos subjetivos y sociales de estas hijas e hijos desde una idea de heroísmo ético o moral.

15 Para Jelin (2017) si, en un primer momento, las denuncias y reclamos de los organismos debieron ser realizados en términos de parentesco, porque la legitimación en la sangre era la única que podía ser expresada cuando todavía imperaba la dictadura, actualmente, para la autora, el familismo conduce a formas
}

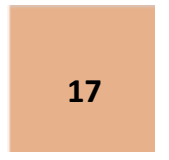

Cuadernos del CILHA n $34-2021$ 
operación paradójica que complejiza el familismo. Por un lado, mantienen el vínculo de parentesco y la afectación sufrida dentro del ámbito familiar - en este caso se trata del lazo biológico con represores y no con víctimas - como fuente de legitimación de la palabra y de las demandas en el espacio público, pero, por otro lado, al quebrar las relaciones con sus progenitores, se rebelan contra la sangre como fundamento de las identidades. En este sentido, creo que la fuerza del testimonio y la presencia en el espacio público de estas hijas proviene de su capacidad para exhibir que los sujetos tienen la posibilidad de hacer otra cosa con los legados, que pueden rebelarse a la sangre e intentar ir más allá de un destino trágico. $Y$ en dichas aperturas y desplazamientos - como veremos en el próximo apartado- las mujeres y el feminismo tienen un papel central.

\section{Armar lazos y genealogías de mujeres}

En la presentación del segundo libro de Historias desobedientes, Patricia Violi (2020b) señalaba que el colectivo posee marcas de género centrales para explicar las posibilidades personales y sociales de correrse de los mandatos familiares patriarcales y filiarse a nuevas creencias y afectividades. El surgimiento y la organización del grupo evocan al affidamento, práctica de autoconciencia entre mujeres del feminismo italiano de los años setenta y ochenta, que suponía una relación de confianza, una alianza entre una mujer que deseaba y una mujer que poseía cierto saber y podía ayudarla a lograr lo que quería. Fue una práctica que intentó dar fuerza a las mujeres y crear genealogías simbólicas femeninas (Lonzi, 2017; Colectivo de la Librería de Mujeres de Milán, 1993; Irigaray, 1992).

Los gestos mediante los que las hijas desobedientes se convocaron unas a otras rememoran ese espíritu de apoyo mutuo en la consecución de un objetivo, que solo puede cumplirse mediante la resistencia - más o menos virulenta - al sistema social patriarcal. Para dar solo algunos ejemplos, la relación de Rita Vagliati y Mariana Dopazo implicó un pasaje afectivo de saber de la primera a la segunda, en tanto que Mariana se basó en la causa de Rita para solicitar a la justicia el cambio de apellido. Durante su

de memoria excluyente porque produce estratificaciones y jerarquizaciones de los sujetos en función de los lazos filiatorios. 
presencia en una mesa redonda titulada "Genocidio y filiación", que versaba sobre la cuestión del cambio de apellido, se cobijaban una a la otra, tocándose las manos, mirándose, sosteniéndose afectivamente (TECME, 2017). Asimismo, Analía Kalinec y Liliana Furió, de Historias desobedientes, mencionan en reiteradas ocasiones que desde que se encontraron se han convertido en "hermanas" inseparables, que comparten entre sí diversos aspectos de sus experiencias actuales y pasadas. ${ }^{16}$ En el caso de Liliana, también el devenir en cuanto a su identidad sexual, su asunción como lesbiana y su acercamiento a la militancia feminista hicieron posible la ruptura con su familia de origen. Escribe:

Mi proceso interno por esta realidad demoledora fue bien largo. Recién cuando me divorcié -en 1994, a los treinta años - y me asumí como lesbiana, pude comenzar un camino crítico y de revisión de todo lo que me habían dicho mis padres y lo que circulaba en el ámbito de la 'familia militar', en donde había vivido hasta entonces. (Bartalini et al., 2018, p. 90)

Pero no es solo en el funcionamiento actual del grupo donde puede observarse la primacía de un vínculo entre mujeres cercano a las prácticas feministas de la "sororidad" (Lagarde, 2006), para usar un término en boga. Las hijas recurren también al pasado para armar genealogías de mujeres. En el ámbito social de la memoria, la genealogía recurrentemente enunciada - pero no por eso menos importante- es la que construyen con las Madres y las Abuelas de Plaza de Mayo, de quienes se nombran como herederas. Algunas de ellas, como Nora Cortiñas y Chicha Mariani, íconos del movimiento de derechos humanos en Argentina, se encargaron de dar señales de cobijo a las hijas desobedientes y asumieron la posición de pasadoras de saber que las hijas les conferían. ${ }^{17}$ El movimiento feminista también las acogió. Durante la marcha por el Paro internacional de mujeres, lesbianas, travestis y trans del 8 de marzo de 2018, ante

\footnotetext{
${ }^{16}$ Liliana Furió es directora y productora de cine documental. Militante feminista. Su padre, Paulino Furió fue jefe de la División Inteligencia (G2) de la VIII Brigada de Infantería de Mendoza. Está condenado a prisión perpetua por delitos de lesa humanidad, pero goza del beneficio de la prisión domiciliaria.

17 Nora Cortiñas participó del Primer Encuentro Primer Internacionališpe Memoria, la Verdad y la Justicia, organizado por Historias Desobedientes y su presentación forma parte del libro (Kalinec et al., 2020) que reúne las presentaciones de dicha jornada. En tanto que, Chicha Mariani se encontró personalmente en privado con Mariana Dopazo (Canal Encuentro, 2020).
}

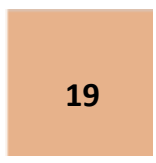

Cuadernos del CILHA n $34-2021$ 
la reciente aparición de la voz de las hijas de represores, el documento leído las incorporó al amplio espectro de los lazos feministas.

Desde el movimiento feminista, evidenciamos el engranaje entre la familia patriarcal y el terrorismo de Estado. Escuchamos, también en el transcurso de este año, a las ex hijas de genocidas desafiliarse de sus progenitores, evidenciando cómo la crueldad de los campos de concentración se traducía en crueldad en la intimidad del entorno familiar. Repudiamos que se les conceda prisión domiciliaria a los represores. Nosotras volvemos a gritar que la única casa de los genocidas es la cárcel. Que no olvidamos ni nos reconciliamos. Y que desde el feminismo estamos construyendo una casa contra todas las formas de crueldad con que el capitalismo quiere aterrorizar nuestras desobediencias. (LATFEM, 2018)

Asimismo, en sus relatos, las hijas examinan el pasado personal buscando claves de lo que son hoy y descubren en sus madres, pero sobre todo en la generación de sus abuelas las chispas de la desobediencia y el afecto que las sostiene. Ana Cacopardo habla de una "revisión feminista de la biografía" para aludir al modo en que Mariana recuerda la vida junto a su abuela materna y sus tías abuelas para construir un linaje de mujeres fuertes y desobedientes. Se trata de una abuela que parece haber iluminado el camino de la nieta al referirse a Etchecolatz como "mal bicho" o "el innombrable". Así lo rememora Mariana:

[L]a infancia en Avellaneda viviendo en la casa de los abuelos maternos fue la plataforma que, me di cuenta muchos años después, me posibilitó que yo no de un salto al vacío, que yo pueda desafiliarme del horror porque me di cuenta de que antes había habitado algo bueno. Una abuela que hacia asados con maderas en la terraza mientras nosotros jugábamos. Maravillosa. [...] [Este] linaje materno que a mí me permite..., ellas eran minas desobedientes también, no se quedaban, no agachaban la cabeza, eran minas independientes para la época, [...] saliendo a laburar espléndidas, pensando cómo armar una vida... (Canal Encuentro, 2020) 
En la novela de Duacastella también la abuela es una figura desobediente y amorosa. "Mi abuela Lidia, la persona que me quiso hasta el cielo, nació en Asunción del Paraguay" (2020, p. 141), se lee al comienzo del capítulo que narra su historia de vida. La abuela es una mujer que se rebeló ante su marido, conformó una extensa biblioteca con la que aprendió a leer y les enseñó a hacerlo a sus criados, se enamoró de otros hombres, se exilió en Argentina tras huir del gobierno de Stroessner y tuvo el coraje de volver a empezar otra vida.

La construcción de lazos de confianza y de genealogías femeninas desobedientes muestran cómo detrás de la posibilidad de confrontación de las hijas hay otras mujeres que las están sosteniendo real y simbólicamente. Estos linajes feministas intentan elidir lógicas masculinistas del poder y resisten el ethos militar-policial-patriarcal, que valora lo masculino en detrimento y negación de lo femenino. En varios de los relatos aflora el tópico de la decepción del padre ante la llegada al mundo de la hija mujer. "La lucha contra el patriarcado la empecé cuando nací. Porque nací mujer, cuando esperaban un varón", escribe Lorna Milena como si el nacimiento hubiera sido su primer gesto de desobediencia (Bartalini et al. 2018, p. 106) ${ }^{18}$.

\section{A modo de conclusión}

En 2017, un contexto global de avanzada de las derechas, un grupo de hijas de represores, que cuestionan los actos criminales de sus padres durante la última dictadura militar argentina, tomaron la palabra, se hicieron visibles en el espacio público y fueron cobijadas tanto por personalidades de los derechos humanos como por el movimiento feminista y de mujeres. A partir de ese momento, han roto con los pactos de silencio y han producido múltiples formas de resistencia a las relaciones de poder en las que estaban insertas, incluidos legados familiares y patriarcales. Se trata de una voz disruptiva que - dada su novedad- aún está produciendo aperturas y efectos sociales, a causa de su potencial para dislocar los discursos negacionistas,

\footnotetext{
${ }^{18}$ Lorna Milena nació en Formosa, es escritora e integrante de Historias desobedientes, hija de un militar muerto impune en 2008. Hace años que escribe sus experiencias y memorias en el blog https://hijademilico.blogspot.com/
} 
reconciliatorios y "dialoguistas" de las nuevas derechas (Saferstein y Goldentul, 2019). En cada coyuntura política hay diferentes memorias y versiones sobre el pasado que se inscriben en escenarios de disputa y negociación.

Las narrativas testimoniales de estas hijas, atravesadas por perspectivas feministas, proveen una entrada para entender las desiguales dinámicas de género - tanto la dominación como las confrontaciones - presentes en el universo de la vida cotidiana de las familias de los represores y aportan datos hasta ahora desconocidos sobre los valores, creencias y comportamientos de los agentes de la represión clandestina durante el terrorismo de Estado. Si bien no se puede hablar de causalidades, los relatos iluminan ciertos entrelazamientos entre violencias sociales, políticas y familiares que colaboran en los procesos de memoria del pasado reciente.

Como describen en sus narraciones, las hijas crecieron en hogares en los que predominaba un ethos militar y policial que valora lo masculino en detrimento y negación de lo femenino. En ese sentido, la construcción de lazos y genealogías entre mujeres representa no solo un acto de resistencia a la ley del padre sino también la posibilidad de formas novedosas de relaciones sociales éticas y políticas. Estas hijas hurgan en el pasado para encontrar modelos -en sus abuelas, en sus madres, en la Madres y Abuelas de Plaza de Mayo- de mujeres amorosas, fuertes y desobedientes que las guíen en el camino de las resistencias a los legados familiares, a la vez que, en sus lazos evocan las prácticas de autoconciencia feminista, la sororidad, el affidamento. Nada mejor que la casa del feminismo, donde la biología no es destino, como espacio en el que encontrar las herramientas necesarias para ir más allá del destino trágico que les correspondía por ser hijas de quienes violaron las leyes de la humanidad.

\section{Referencias}

Ahmed, S. (2019). La promesa de la felicidad. Una crítica cultural al imperativo de la alegría. Caja Negra.

Arenes, C. y Pikielny, A. (2016). Hijos de los 70. Historias de la generación que heredó la tragedia argentina. Sudamericana

Arfuch, L. (2017) Nuevas voces de la memoria. Las otras infancias clandestinas. Revista Anfibia. http://www.revistaanfibia.com/ensayo/las-otras-infancias-clandestinas/

Bartalini, C. et al. (2018). Escritos desobedientes. Historias de hijas, hijos y familiares de genocidas por la memoria, la verdad y la justicia. Marea Editorial 
Basile, T. (2020). Padres perpetradores. Perspectivas desde los hijos e hijas de represores en Argentina, Kamchatka. Revista de Análisis cultural, 15.

Calveiro, P. (2005). Familia y poder. Libros de la Araucaria.

Canal Encuentro. (2020). Historias debidas IX: Mariana Dopazo (Capítulo 1). [video] Youtube https://www.youtube.com/watch?v=eFZQSrBQaME

Colectivo de la Librería de Mujeres de Milán (1993). No creas tener derechos. Debate feminista, 7, 235-248.

Colectivo Historias Desobedientes (2020, 24 de marzo). Llamado a la desobediencia. [video]

https://www.facebook.com/watch/?v=3899356686787569

Crownshaw, R. (2011). Perpetrator Fictions and Transcultural Memory. Parallax, 17 (4), 75-89.

Dopazo, M. (2020). Más allá de un padre. En A. Kalinec (comp.). Nosotrxs, historias desobedientes. Ediciones AMP.

Dores, A. (directora). (2019) Hija Indigna [película]. ENERC.

Duacastella, S. (2020). La mujer sin fondo. Nomeolvides.

Feierstein, D. (2007). El genocidio como práctica social. Fondo de Cultura Económica.

Feld, C. y Salvi, V. (2016). Presentación. Cuando los perpetradores hablan. Dilemas y tensiones en torno a una voz controvertida. Rubrica Contemporanea, 5 (9), 1-10.

https://revistes.uab.cat/rubrica/article/view/v5-n9-feld-salvi

Feld, C. y Salvi, V. (2019). Introducción. Declaraciones públicas de represores de la dictadura argentina: temporalidades, escenarios y debates. En Las voces de la represión. Declaraciones de perpetradores de la dictadura argentina (pp. 10-56). Miño y Davila.

Filc, J. (1997). Entre el parentesco y la política. Familia y dictadura, 1976-1983. Biblos.

Fries, L. (2010). El caso chileno y la violencia de género". En M. Sondereguer y V. Correa (eds.), Violencia de género en el terrorismo de Estado: Políticas de memoria, justicia y reparación (pp. 26-33). Universidad de Quilmes.

Gómez Groppa. M. L. (2020). Desobedientes: en torno a las narrativas de posdictadura, la memoria y el feminismo en Argentina. MILLCAYAC. Revista Digital de Ciencias Sociales, VII (12), 129-140.

https://revistas.uncu.edu.ar/ojs/index.php/millca-digital/article/view/2625

Gondeltul, A. (2016) Represor. En Proyecto: diccionario del pensamiento alternativo II, CECIES, Pensamiento Latinoamericano y alternativo. http://cecies.org/articulo-completo. php?idarticle=101

Guglielmucci, A. (2020). Historias Desobedientes. Memorias de hijos y nietos de perpetradores de crímenes de lesa humanidad en Argentina. Revista Colombiana de Antropología, 56 (1), 15-44.

http://dx.doi.org/10.22380/2539472X.1045

Irigaray, L. (1992). Yo, tu, nosotras. Cátedra.

Jelin, E. (1998). Pan y afectos. La transformación de las familias. Fondo de Cultura Económica.

Jelin, E. (2017). La lucha por el pasado. Siglo XXI.

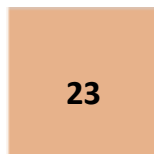

Cuadernos del CILHA n $34-2021$ 
El género de la desobediencia: resistencias al legado familiar en las hijas de represores en Argentina

Kalinec, A. et al. (2020). Nosotrxs, historias desobedientes. Ediciones AMP.

Lagarde y de los Ríos, M. (2005). Los cautiverios de las mujeres. Madresposas, monjas, putas, presas, locas. UNAM.

Lagarde y de los Ríos, M. (octubre, 2006). Pacto entre mujeres, sororidad. https://www.asociacionag.org.ar/pdfaportes/25/09.pdf

LATFEM (2018, 7 de marzo). Documento completo del Paro Internacional de mujeres, lesbianas, travestis y trans \#8M en Argentina. LATFEM. http://latfem.org/documento-de-la-asamblea8m-de-argentina-parointernacional-de-mujeres-lesbianas-travestis-y-trans/

Lazzara, M. (2020). Familiares de colaboradores y perpetradores en el cine documental chileno: memoria y sujeto implicado. Atenea, 521, 231-248. http://dx.doi.org/10.29393/at521-16fmjl10016

Lipis, G. (2019). No lo perdono. El testimonio de Erika Lederer, hija de un médico obstetra genocida. Planeta. Llonto, P. (2020). Las leyes que faltan. En A. Kalinec (comp.). Nosotrxs, Historias desobedientes. Ediciones AMP.

Lonzi, C. (2017). Escupamos sobre Hegel. Tinta Limón.

Mannarino, J.M. (2017). Mariana, la hija de Etchecolatz. Marché contra mi padre genocida. Revista Anfibia. http://revistaanfibia.com/cronica/marche-contra-mi-padre-genocida/

Moral, J., Bayer, G. y Canet, F. (2020). Facing the perpetrator's legacy: post-perpetrator generation documentary films, Continuum, Journal of Media \& Cultural Studies, 34.

https://doi.org/10.1080/10304312.2020.1737436

Oberti, A. (2015). Las revolucionarias. Militancia, vida cotidiana y afectividad en los setenta. Edhasa.

Pedrido, V. (2021). Cartografía argumentativa de los sectores fundamentalistas/conservadores. Casa Fusa. https://grupofusa.org/wp-content/uploads/2021/05/Cartografia-argumentativa-de-los-sectoresconservadores-fundamentalistas-1-2-1.pdf

Peller, M. (2020). Hijas aguafiestas: memorias y experiencias de la segunda generación en Argentina. En T.

Basile, C. González (coord.) Las posmemorias. Perspectivas latinoamericanas y europeas/ Les postmémoires. Perspectives latino-américaines et européennes. Prensas Universitarias de Bordeaux (PUB) y Universidad Nacional de la Plata.

Raso, L. (2017). Nuevas Antígonas: las parresiastas. Sobre Historias desobedientes y con faltas de ortografía". [ponencia] Congreso Políticas de la Memoria], Centro Cultural de la Memoria Haroldo Conti.

Rothberg, M. (2019). The Implicated Subject: Beyond Victims and Perpetrators. Stanford University Press.

Rousseaux, F. (5 de julio de 2018). Genocidio, filiación y transmisión. Página 12.

https://www.pagina12.com.ar/126261-genocidio-filiacion-y-transmision

Saferstein, E. y Goldentul, A. (noviembre 2019). El “diálogo" como discurso emergente. La articulación de un espacio de ideas en torno a la memoria del pasado reciente en Argentina (2008-2018). Políticas de la Memoria, revista de investigación del CEDINCI, 19, 15-30. https://doi.org/10.47195/19.586 
Santucho, M. (27 de julio 2017). Historias desobedientes o hijos de genocidas. Revista Crisis, 30. https://revistacrisis.com.ar/notas/historias-desobedientes-o-hijos-de-genocidas

Scocco, M. (2017). Historias desobedientes. ¿Un nuevo ciclo de memoria?, Sudamérica, 7, 78-105. https://fh.mdp.edu.ar/revistas/index.php/sudamerica/article/view/2532

Snyder, R. L. (2019). No Visible Bruises. What We Don't Know About Domestic Violence Can Kill Us. Bloomsbury.

Sutton, B. (2018). Surviving State Terror. Women's Testimonies of Repression and Resistance in Argentina. New York University Press.

TECME (2017, 2 de agosto). Genocidio y filiación. Hacerse un nombre frente a los legados sin ley [video]. Youtube https://www.youtube.com/watch?v=0EiUPXTUcw4

Violi, P. (2020a) Los engaños de la posmemoria. Tópicos del seminario, 44, 12-28.

http://www.topicosdelseminario.buap.mx/index.php/topsem/article/view/698

Violi, P. (2020b, 26 de mayo). Presentación Nosotrxs, Historias desobedientes. [video] Youtube. https://www.youtube.com/watch?v=hgypK-ZBrOA

Zylberman, L. (2020). Against family loyalty: documentary films on descendants of perpetrators from the last Argentinean dictatorship, Continuum, Journal of Media \& Cultural Studies, 34 (2), 241-254.

https://doi.org/10.1080/10304312.2020.1737435 